\title{
Development of a Serum-Free System to Expand Dental-Derived Stem Cells: PDLSCs and SHEDs
}

\author{
S.A. TARLE,' S. SHI, ${ }^{2}$ AND D. KAIGLER ${ }^{1,3,4 *}$ \\ 'Department of Periodontics and Oral Medicine, University of Michigan, Ann Arbor, Michigan \\ ${ }^{2}$ Center for Craniofacial Molecular Biology, School of Dentistry, University of Southern California, Los Angeles, California \\ ${ }^{3}$ Michigan Center for Oral Health Research, University of Michigan, Ann Arbor, Michigan \\ ${ }^{4}$ Department of Biomedical Engineering, University of Michigan, Ann Arbor, Michigan
}

\begin{abstract}
Recently, extracted teeth have been identified as a viable source of stem cells for tissue regenerative approaches. Current expansion of these cells requires incorporation of animal sera; yet, a fundamental issue underlying cell cultivation methods for cell therapy regards concerns in using animal sera. In this study, we investigated the development of a chemically defined, serum-free media (K-M) for the expansion of human periodontal ligament stem cells (PDLSCs) and human stem cells from exfoliated deciduous teeth (SHEDs). Proliferation assays were performed comparing cells in serum-containing media (FBS-M) with cells cultured in four different serum-free medium and these demonstrated that in these medium, the cell proliferation of both cell types was significantly less than the proliferation of cells in FBS-M. Additional proliferation assays were performed using pre-coated fibronectin (FN) tissue culture plates and of the four serum-free medium, only K-M enabled PDLSCs and SHEDs to proliferate at higher rates than cells cultured in FBS-M. Next, alkaline phosphatase activity showed that PDLSCs and SHEDs exhibited similar osteogenic potential whether cultured in K-M or FBS-M, and, additionally, cells retained their multipotency in K-M as seen by expression of chondrogenic and adipogenic genes, and positive Von Kossa, Alcian blue, and Oil Red O staining. Finally, differential expression of 84 stem cell associated genes revealed that for most genes, PDLSCs and SHEDs did not differ in their expression regardless of whether cultured in K-M or FBS-M. Taken together, the data suggest that K-M can support the expansion of PDLSCs and SHEDs and maintenance of their multipotency.

J. Cell. Physiol. 226: 66-73, 2010. (C) 2010 Wiley-Liss, Inc.
\end{abstract}

Cell therapy has tremendous potential in regenerative medicine, yet, there are concerns in the utility of cell therapy due to questions regarding different cell harvest and cultivation methods (Mannello and Tonti, 2007; Haack-Sorensen et al., 2008). Bone marrow derived stem cells have been identified for a number of years, and there are several of ongoing clinical trials exploring the safety and efficacy of their use for different of clinical applications (Battiwalla and Hematti, 2009; Sadan et al., 2009; Satija et al., 2009). There has been an increased interest in recent years in the potential of oral-derived stem cells for cell therapy, primarily because they can be derived from a readily available source, extracted teeth (Gronthos et al., 2000; Miura et al., 2003; Seo et al., 2004). These cells exhibit multipotency and regenerative capacities characteristic of mesenchymal stem cells (Batouli et al., 2003; Shi et al., 2005) and have the capacity to repair and regenerate tooth structures in vivo (Krebsbach and Robey, 2002; Mao et al., 2006). Because oral-derived stem cells have been more recently identified, clinical protocols are still being developed for their use. Regardless of the specific protocol used, most current cell therapy approaches rely upon ex vivo cell expansion in order to produce sufficient cell numbers for transplantation. Though a wide variety of protocols and culturing methods exist, one common aspect to most of them is the inclusion of animal sera for cell expansion, in that it contains a rich source of nutrients and growth factors (Mannello and Tonti, 2007). Despite the widespread standard use of animal sera for in vitro cell culture (Freshney, 2000), there are several problems which exist relative to its use for clinical application.

One of the central issues regarding limitations in using animal sera for clinical cell therapy protocols is that its components are highly variable and, in many cases, unknown. Though components of sera have been identified, it has also been demonstrated that consistency between different lots cannot be assured (Price and Gregory, 1982). In the context of multipotent stem cells, serum components and concentrations have significant impact on cell survival and proliferative capacity, phenotype, and multipotent potential (Sotiropoulou et al., 2006; Agata et al., 2009). Additionally, for clinical use, the inclusion of xenogeneic serum for cell expansion carries immunological risks associated with the immunogenicity of serum proteins and the potential of transmission of prion diseases and zoonoses (Shahdadfar et al., 2005). These concerns have led to efforts aimed at incorporating FBS alternatives in cell expansion protocols, including the use of autologous and allogeneic sera, and the proprietary manufacturing of serum-free media formulations by different companies (Nakamura et al., 2008). Even with these approaches, there are limitations in the availability of both autologous and allogeneic sera and companies do not freely disclose their proprietary "serum-free" media components. These factors not only prohibit clinical translation, but also limit widespread use and study of more basic fundamental questions regarding specific mechanisms involved in the modulation of these media on cell function. As such, there exists a need for the development of chemically defined media which can propagate the cultivation of stem cells without adversely affecting cell function and phenotype (Mannello and Tonti, 2007).

Contract grant sponsor: Burroughs Wellcome Fund;

Contract grant number: CAMS-1006918.

*Correspondence to: D. Kaigler, Department of Periodontics and Oral Medicine, University of Michigan, I0II N. University, Ann Arbor, MI 48I09. E-mail: dkaigler@umich.edu

Received 13 May 2010; Accepted 23 June 2010

Published online in Wiley Online Library

(wileyonlinelibrary.com.), 12 July 2010.

DOI: $10.1002 / j c p .22304$ 
In this study, we aimed to develop a serum-free media (K-M) for the expansion of dental-derived stem cells, including stem cells-derived from exfoliated deciduous (baby) teeth (SHEDs) and periodontal ligament stems cells (PDLSCs). Cell expansion in this media was compared to standard FBS containing media used to culture these cells, as well as three other serum-free media formulations (two of which are commercially available) used for culture of mesenchymal stem cells. Additionally, through differentiation assays and microarray analyses, multipotency and differential gene expression of 84 stem cell associated genes was examined between cells cultured in K-M versus those cultured in FBS-containing media.

\section{Materials and Methods}

Isolation of dental-derived stem cells (PDLSCs, SHEDs)

PDLSCs and SHEDs were harvested as previously described (Miura et al., 2003; Seo et al., 2004). Briefly, PDLSCs were scraped from the root surface of a tooth into a 600 dish containing minimum essential alpha medium ( $\alpha$ MEM, Gibco, Carlsbad, CA) and SHEDs were harvested by scraping out the dental pulp tissue from a deciduous tooth into a p60 dish containing $\alpha$ MEM. After collection, the cells were centrifuged at I,600 rpm for $5 \mathrm{~min}$ at room temperature. The supernatant was aspirated and the cells were resuspended in a phosphate buffered saline (PBS; Gibco \#14190) solution with $4 \mathrm{mg} / \mathrm{ml}$ Dispase II (Roche \#04 942078 00I) and $2 \mathrm{mg} / \mathrm{ml}$ Collagenase Type II (Worthington \#LS004196) and incubated at $37^{\circ} \mathrm{C}$ for $60 \mathrm{~min}$. The enzyme solution was inactivated with $5 \mathrm{ml}$ of $\alpha$ MEM-I5\% FBS- $100 \mu \mathrm{M}$ ascorbic acid 2 phosphate (ASAP, Sigma A-8960, St. Louis, MO) and centrifuged at I,600 rpm for $5 \mathrm{~min}$ at room temperature. Cells were resuspeneded in $5 \mathrm{ml}$ $\alpha$ MEM-I5\% FBS-0.I mM ASAP and transferred to T-25 flasks. Media was changed the next day and then every 2-3 days.

\section{Cell culture}

Cells were expanded in culture in $\alpha$ MEM, Iscove's modified Dulbecco's media (IMDM, Gibco-Invitrogen \# I257I), Gibco Stem Pro Mesenchymal Stem Cell Serum-Free Media (MSCSFM; Invitrogen \#A I03340I, Carlsbad, CA) or Lonza Therapeak Mesenchymal Stem Cell Growth, Media-Chemically Defined (Walkersville, MD) (MSCGM-CD; Lonza \#00190632) and grown in a $37^{\circ} \mathrm{C}$ humidified tissue culture incubator at $5 \% \mathrm{CO}_{2}$. Media formulations are as follows: $\alpha$ Mem (Gibco-Invitrogen \#I257I) with I5\% FBS (Gibco-Invitrogen-16000), $100 \mu$ M ASAP and $5 \mu g /$ ml Gentamicin (Invitrogen \# I5750060) (FBS-M); $\alpha$ Mem with $2 \%$ bovine serum albumin (BSA; Sigma A7888), $10 \mu \mathrm{g} / \mathrm{ml}$ human insulin (Sigma), $4 \mu \mathrm{g} / \mathrm{ml}$ low density lipoprotein, $200 \mu \mathrm{g} / \mathrm{ml}$ transferrin, $10 \mathrm{nM}$ dexamethasone, $100 \mu \mathrm{M}$ ASAP, $50 \mu \mathrm{M} \beta$-mercaptoethanol, $5 \mu \mathrm{g} / \mathrm{ml}$ gentamicin, $10 \mathrm{ng} / \mathrm{ml}$ platelet-derived growth factor (PDGF; Sigma), $10 \mathrm{ng} / \mathrm{ml}$ epidermal growth factor (EGF; R\&D Systems), $10 \mathrm{ng} / \mathrm{ml}$ basic fibroblast growth factor (b-FGF, Sigma) (SDM); IMDM with 0.2\% BSA, SITE 3 (Sigma \#S5295), $384 \mu \mathrm{M}$ ASAP, $10 \mathrm{ng} / \mathrm{ml}$ PDGF, $10 \mathrm{ng} / \mathrm{ml}$ hydrocortisone $5 \mathrm{ng} / \mathrm{ml}$ b-FGF, $\mathrm{I} \mathrm{ng} / \mathrm{ml} \mathrm{EGF}, 10^{-7} \mathrm{mg} / \mathrm{ml}$ parathyroid hormone (PTH) and $5 \mu \mathrm{g} / \mathrm{ml}$ gentamicin (K-M). Media on the cells were changed every 2 or 3 days. Cells were grown in T-I 50 flasks to about $80 \%$ confluency then media was aspirated from the flasks, cells were washed with PBS and trypsinized with TrypLE Express (Gibco \#12605) before being split into 12 well plates for the assays.

\section{Fibronectin coating of tissue culture plates}

Fibronectin (FN) was coated on the plates and flasks to provide growth and attachment support for cells grown in the serum-free, IMDM media. For the 12 well plates, 0.1\% FN solution (Sigma F-I I4I) was diluted in PBS so that each well received $3.8 \mu \mathrm{g}$ per well $\left(I \mu g \mathrm{FN} / \mathrm{cm}^{2}\right)$. The T-I50 flasks were coated so that each received I50 $\mathrm{gg}$ of $\mathrm{FN}\left(\mathrm{I} \mu \mathrm{gFN} / \mathrm{cm}^{2}\right)$. The plates and flasks were tilted back and forth to ensure complete coverage of the FN solution. The FN coating was allowed to stand at room temperature for $90 \mathrm{~min}$. The FN solution was then aspirated before the resuspended cells were transferred to the flasks and plates.

\section{Proliferation assays}

After trypsinization cells were resuspended in an equal amount of the appropriate media before an aliquot was removed for counting on a hemocytometer to determine the concentration. The cells were then centrifuged at $\sim 1,600 \mathrm{rpm}$ for $5 \mathrm{~min}$ at room temperature. Cells were resuspended in the appropriate media at a concentration of 3,800 cells $/ \mathrm{ml}$. One milliliter of cells was dispensed into each well of a 12 well plate. K-M plates were precoated with FN solution (as outlined above). Four plates for each cell type and media condition were plated and counted on a hemocytometer at Days I, 3, 5, and 7 to determine the cell numbers within each well. All experiments were performed in triplicate.

\section{RNA isolation and purification for microarray}

PDLSCs and SHEDs were grown in T-75 flasks to $80 \%$ confluency before the cells were harvested for RNA. The Trizol method (Invitrogen) was used for RNA isolation. This involved adding Trizol directly to the cells and transferring this cell suspension to polypropylene tubes. RNA was isolated from the cells by a Trizol-choloroform extraction, isopropanol precipitation, an ethanol rinse and resuspension of the RNA pellet in Diethylpyrocarbonate (DEPC) water. The RNA was further purified by column chromatography, following manufacturer's instructions (Qiagen RNeasy Kit \#74104), and resuspended in DEPC water. RNA concentration was determined by the $260 / 280$ absorbance measurement using a Beckman DU540 spectrophotometer.

\section{In vitro multilineage differentiation}

Multipotency of PDLSCs and SHEDs was determined through lineage specific osteogenic, chondrogenic, and adipogenic induction, according to previously described methods (Pittenger et al., 1999). Briefly, cells were plated at a density of 30,000 cells/well in 12 well plates. At $80 \%$ confluency cells were induced with osteogenic [growth media plus $5 \mathrm{mM} \beta$-glycerophosphate, $100 \mathrm{nM}$ dexamethasone, $50 \mu \mathrm{M}$ ascorbic acid 2-phosphate] or chondrogenic [growth media plus $50 \mu \mathrm{M}$ ascorbic acid 2-phosphate, $100 \mathrm{nM}$ dexamethasone, $5 \mu \mathrm{g} / \mathrm{ml}$ human insulin (Sigma l-9278), I ng/ml TGF $\beta, 400 \mu$ M proline, I $\times$ non-essential amino acids] or adipogenic [growth media plus $0.5 \mathrm{mMIBMX}, \mathrm{I} \mu \mathrm{M}$ dexamethasone, $10 \mu \mathrm{g} / \mathrm{ml}$ human insulin, $200 \mu \mathrm{M}$ indomethacin] induction media. Cells were grown at $37^{\circ} \mathrm{C}$ in a humidified $5 \% \mathrm{CO}_{2}$ incubator. The media was changed every $2-3$ days. At 3 weeks the cells were fixed and stained as outlined below.

\section{Multipotent staining of PDLSCs and SHEDs}

To identify the mineralized nodules, induced PDLSCs and SHEDs were fixed in $4 \%$ paraformaldehyde for $30 \mathrm{~min}$, immersed in fresh $5 \%$ silver nitrate and incubated in the dark for $30 \mathrm{~min}$. After washing in water the PDLSCs and SHEDs were exposed to ultraviolet light for $30 \mathrm{~min}$ followed by a $4 \mathrm{~min}$ incubation in $1 \%$ sodium thiosulfate to neutralize the silver nitrate. Cells were washed twice with water before I $\mathrm{ml}$ of PBS was added to each well and viewed. Plates were stored at $4^{\circ} \mathrm{C}$.

To detect chondrogenic differentiation induced PDLSCs and SHEDs were fixed in cold $100 \%$ methanol for 30 min and then exposed to $1 \%$ alcian blue in $0.1 \mathrm{~N} \mathrm{HCl}$ for $30 \mathrm{~min}$. Cells were washed twice with $0.1 \mathrm{~N} \mathrm{HCl}$ before I ml of PBS was added to each well and viewed. Plates were stored at $4{ }^{\circ} \mathrm{C}$.

To detect adipogenic differentiation by identifying lipid vesicles, induced PDLSCs and SHEDs were fixed in $4 \%$ paraformaldehyde 
for $30 \mathrm{~min}$, and then immersed in $0.3 \%$ oil red $O$ solution for $30 \mathrm{~min}$. Cells were washed twice with water before I $\mathrm{ml}$ of PBS was added to each well and viewed. Plates were stored at $4{ }^{\circ} \mathrm{C}$.

\section{Alkaline phosphatase activity and detection}

Early osteogenic differentiation was detected and quantified by the alkaline phosphatase (ALP) enzyme assay. Cells were plated at a density of 30,000 cells/well in 12 well plates. At $80 \%$ confluence, cells were induced with osteogenic media as described above. The media was changed every 2-3 days and after I week, ALP activity was measured.

To detect phosphatase activity, PDLSCs and SHEDs were fixed in $70 \%$ ethanol for $30 \mathrm{~min}$. They were then incubated with freshly made substrate containing naphthol AS-TR phosphate (Sigma) and Fast blue (Sigma) for $30 \mathrm{~min}$. Cells were washed twice with PBS then viewed or stored at $4^{\circ} \mathrm{C}$.

To quantify the ALP activity and normalize the results, cells were lysed in Passive Lysis Buffer (Promega, Madison, WI) according to manufacturer's instructions. Cell lysates were then sonicated, and centrifuged $\left(10,000 \mathrm{rpm}\right.$ for $10 \mathrm{~min}$ at $\left.4^{\circ} \mathrm{C}\right)$. The supernatant was recovered for the quantitative colormetric ALP assay (Manolagas et al., 198I) and the cell pellet was used for DNA isolation and the determination of the DNA concentration using the Quant-iT ${ }^{\mathrm{TM}}$ dsDNA BR Assay (Invitrogen) per the manufacturer's instructions.

\section{Reverse transcriptase polymerase chain reaction (RT-PCR)}

To confirm chondrogenic and adipogenic differentiation, total PDLSC and SHED cellular RNA was extracted, reverse transcribed, and amplified using osteoblast specific gene primers. Media from the wells of induced and uninduced PDLSCs and SHEDs were aspirated. Cells were immediately resuspended in I $\mathrm{ml}$ of Trizol (Invitrogen) and RNA was isolated according to the manufacturer's instructions. Synthesis of cDNA was performed using Invitrogen's SuperScriptll kit and oligo dT. PCR reaction components and concentrations were as described in the Invitrogen Platinum Taq polymerase instructions using the primer sets below. An MJ themorcycler was used for the following two $P C R$ reaction conditions:

$$
\begin{aligned}
* 94^{\circ} \mathrm{C} 2 \text { minutes } & \rightarrow\left[94^{\circ} \mathrm{C} 45^{\prime \prime} \rightarrow 56^{\circ} \mathrm{C} 45^{\prime \prime} \rightarrow 72^{\circ} \mathrm{Cl}^{\prime}\right] \\
& \times 35 \text { cycles } \rightarrow 72^{\circ} \mathrm{C} \mathrm{I5^{ \prime }}
\end{aligned}
$$

or

$$
\begin{aligned}
* 94^{\circ} \mathrm{C} 2 \text { minutes } & \rightarrow\left[94^{\circ} \mathrm{C} 45^{\prime \prime} \rightarrow 67^{\circ} \mathrm{C} 45^{\prime \prime} \rightarrow 72^{\circ} \mathrm{Cl}^{\prime}\right] \\
& \times 35 \text { cycles } \rightarrow 72^{\circ} \mathrm{C} \mathrm{I5^{ \prime }}
\end{aligned}
$$

\begin{tabular}{|c|c|c|c|}
\hline $\begin{array}{l}\text { Primer } \\
\text { name }\end{array}$ & $\begin{array}{l}\text { Primer } \\
\text { sequence }\end{array}$ & $\begin{array}{l}\text { Product } \\
\text { size (bp) }\end{array}$ & $\begin{array}{l}\text { Accession } \\
\text { number }\end{array}$ \\
\hline $\begin{array}{l}\text { *GAPDH FWD } \\
{ }^{*} \text { GAPDH REV }\end{array}$ & $\begin{array}{l}\text { AGCCGCATCTTCTTTTGCGTC } \\
\text { TCATATTTGGCAGGTTTTTCT }\end{array}$ & 815 & NM_002046 \\
\hline $\begin{array}{l}\text { PPAR } \gamma 2 \text { FWD } \\
\text { PPAR } 2 \text { REV }\end{array}$ & $\begin{array}{l}\text { GCTGTGCAGGAGATCACAGA } \\
\text { GGGCTCCATAAAGTCACCAA }\end{array}$ & 226 & NM_005037 \\
\hline $\begin{array}{l}\text { Lipoprotein } \\
\text { lipase FWD }\end{array}$ & GTCCGTGGCTACCTGTCATT & 212 & NM_000237 \\
\hline $\begin{array}{l}\text { Lipoprotein } \\
\text { lipase REV }\end{array}$ & TGTCCCACCAGTTTGGTGTA & & \\
\hline $\begin{array}{l}\text { Sox } 9 \text { FWD } \\
\text { Sox } 9 \text { REV }\end{array}$ & $\begin{array}{l}\text { TTGAGCCTTAAAACGGTGCT } \\
\text { CTGGTGTTCTGAGAGGCACA }\end{array}$ & 224 & NM000346 \\
\hline $\begin{array}{l}\text { Type } X \\
\text { collagen FWD }\end{array}$ & TGAGCAGCAACGTAAAAACG & 471 & NM_00049 \\
\hline $\begin{array}{l}\text { Type } X \\
\quad \text { collagen REV }\end{array}$ & AGGAAATGCCGAGTTTCTCA & & \\
\hline
\end{tabular}

PCR primer pairs

\section{Statistical analysis}

Statistical analysis was performed with the use of Instat software (GraphPad Software, San Diego, CA). All data were plotted as mean \pm standard error of the mean (SEM), unless otherwise noted. Statistically significant differences were determined by two-tailed Student $t$ tests, and statistical significance was defined as $P<0.05$.

Results

\section{Cell growth and proliferation}

PDLSCs and SHEDs were cultured for 7 days in four different media formulations and their proliferative potential was compared to cells grown in FBS-M. In all serum-free conditions, after 3 days, the cell proliferation of both cell types was $<70 \%$ of the proliferation rate of cells grown in FBS-M and by day 5 , this decreased to $<50 \%$. Neither of the cell types proliferated to the same degree as cells grown in FBS-M, though cells seemed to grow best in the Lonza media and K-M, particularly the SHEDs (Fig. Ia,b). Additionally, relative to cell cultures in the FBS-M, in all cultures grown in serum-free media there were larger numbers of floating and non-adhering cells at Day I and throughout the timecourse of the study. This suggested that the cells did not have sufficient initial adherence, limiting their capacity to sustain cell growth over time.

The next set of studies followed from the first set and aimed to evaluate the cell adhesive and proliferative effect of providing an extracellular matrix (ECM) coating on the cell culture growth surface. PDLSCs and SHEDs were expanded in K-M and Lonza medium and FN was coated on these tissue culture plates prior to plating of cells. Over time, PDLSCs and SHEDs cultured in K-M exhibited morphology no different than those seen in

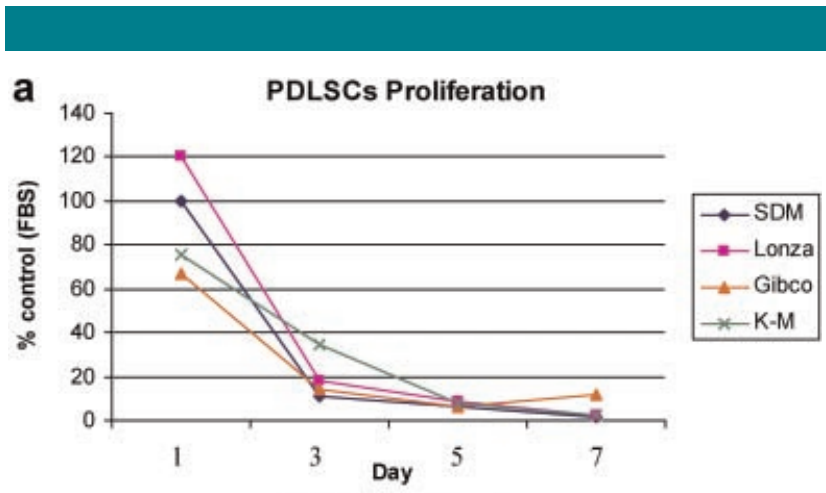

b

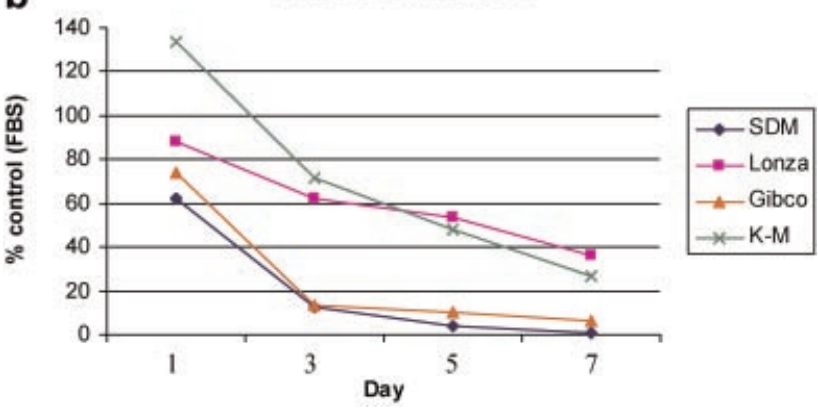

Fig. I. Proliferation of dental-derived stem cells in serum-free media. a: PDLSCs and (b) SHEDs were cultured for 7 days in four different media formulations and their proliferative potential was compared to cells grown in FBS-M. Cell numbers are plotted relative to the same cells grown in FBS during this same time period. [Color figure can be viewed in the online issue, which is available at wileyonlinelibrary.com.] 


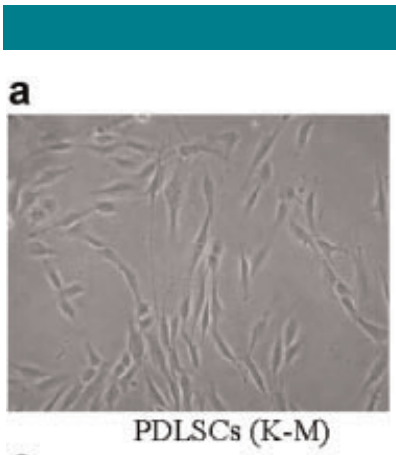

c

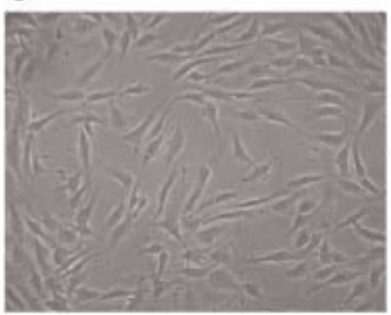

SHEDs (K-M)

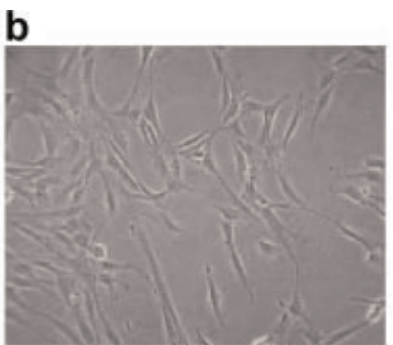

PDLSCs (FBS)

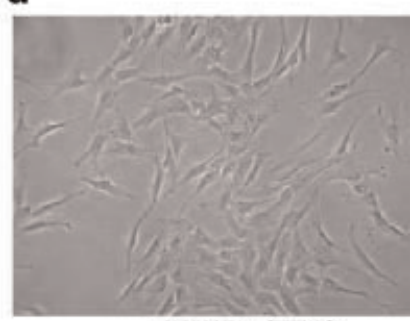

SHEDs (FBS)

e PDLSCs Proliferation

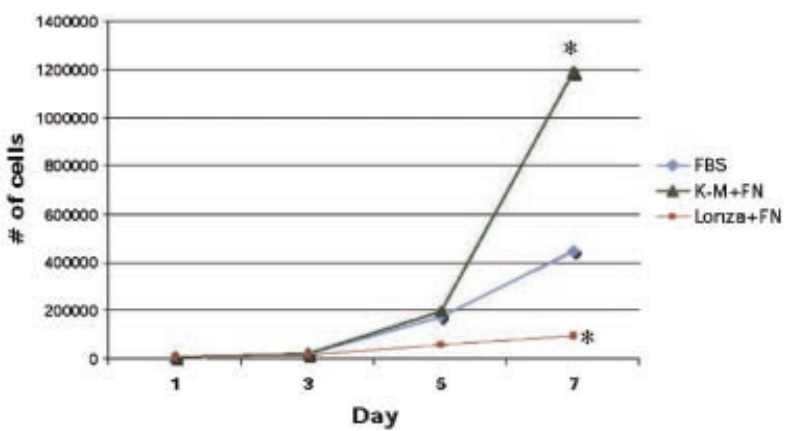

f

SHEDS Proliferation

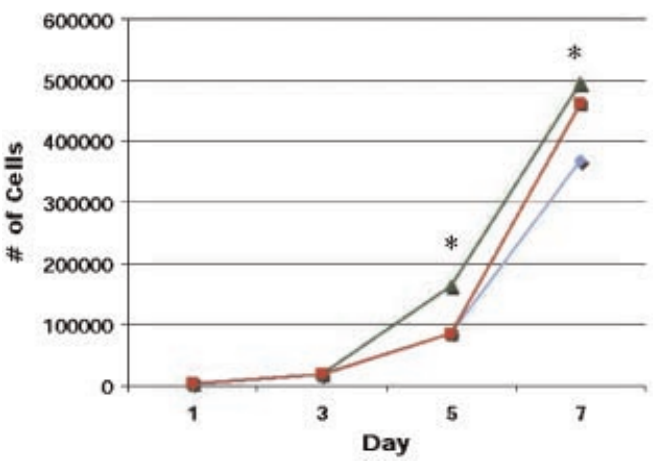

$\rightarrow$ FBS $\pm-K-M+F N$ - LonZa+FN

Fig. 2. Proliferation of dental-derived stem cells in serum-free media with fibronectin (FN). Photomicrographs of PDLSCs in (a) K-M and (b) FBS-M; SHEDs in (c) K-M and (d) FBS-M. Proliferation plots of (e) PDLSCs and (f) SHEDs in serum-free media on plates pre-treated with $\mathrm{FN}$. These data are plotted directly against cells grown in serum containing media (FBS-M). ${ }^{*}$ Denotes $P<0.05$ relative to FBS condition. [Color figure can be viewed in the online issue, which is available at wileyonlinelibrary.com.]

cells cultured in FBS-M (Fig. 2a-d). The proliferation assays revealed that when grown in K-M, PDLSCs in K-M exhibited significantly higher proliferation rates by day 7 (Fig. 2e) when compared to PDLSCs cultured in FBS-M. On the other hand, by day 5 of the 7-day timecourse, SHEDs proliferated at significantly $(P<0.05)$ higher rates than cells in FBS-M (Fig. 2f).

Though the Lonza media supported the proliferation of SHEDs equivalent to that seen in K-M, PDLSCs in this media did not proliferate to the same degree as in the control FBS-M or K-M. Similar proliferation assays were conducted with dental pulp stem cells (DPSCs) and bone marrow derived stem cells (MSCs) and the K-M did not support proliferation of either cell type to the same degree as the FBS-M (data not shown).

\section{Differential gene expression of PDLSCs and SHEDs in $K-M$ versus $F B S-M$}

Both PDLSCs and SHEDs cultured in K-M exhibited a greater proliferative capacity than when cultured in FBS-M, and thus, we next wanted to determine if $\mathrm{K}-\mathrm{M}$ had effects on gene expression of these two cell types. Eighty-four stem cell associated genes were analyzed for differential expression when cells were cultured in K-M relative to when cultured in FBS-M. Following I week of culture in the respective media, genes associated with "stemness" and lineage specific genes were analyzed with RT-PCR microarray and genes exhibiting a greater than twofold difference in expression between the conditions were reported. Table I shows upregulated "stemness" associated genes when PDLSCs were cultured in K-M, relative to FBS-M. Overall, the K-M media appeared to support a significant ( $>2$-fold) upregulation in expression of genes associated with mesenchymal stem cells and "stemness," particularly when compared to downregulated gene expression of "stemness"

TABLE I. Upregulated expression of PDLSC genes in $\mathrm{K}-\mathrm{M}$ versus FBS-M

\begin{tabular}{|c|c|}
\hline Functional gene grouping & Fold incre \\
\hline \multicolumn{2}{|l|}{ Stem cell associated genes } \\
\hline \multicolumn{2}{|l|}{ Markers of "stemness" } \\
\hline Leukemia inhibitory factor (LIF) & 8.0 \\
\hline Insulin & 5.7 \\
\hline Telomerase reverse transcriptase (TERT) & 5.1 \\
\hline Wnt3A & 4.0 \\
\hline Sex determining region $\mathrm{Y}$ (SRY)-box 2 (Sox2) & 3.3 \\
\hline \multicolumn{2}{|l|}{ MSC specific markers } \\
\hline Alanyl aminopeptidase & 66.9 \\
\hline VEGFR-2/KDR & 18.2 \\
\hline Nerve growth factor receptor & 10.2 \\
\hline Prominin I (CDI33) & 8.7 \\
\hline Frizzled homolog 9 (FZD9) & 5.6 \\
\hline Fucosyltransferase 4 (FUT4) & 3.8 \\
\hline Vascular cell adhesion molecule-I (CDI06) & 3.4 \\
\hline NT5E (CD73) & 2.8 \\
\hline Encodes epidermal GF receptor-2 (ERBB2) & 2.6 \\
\hline \multicolumn{2}{|l|}{ Other MSC associated genes } \\
\hline Hepatocyte growth factor & 128.5 \\
\hline Vascular endothelial growth factor-A (VEGF-A) & 13.2 \\
\hline Colony stimulating factor 3 (G-CSF-3) & 12.0 \\
\hline Von Willebrand factor & 10.2 \\
\hline Interferon gamma & 6.4 \\
\hline Epidermal growth factor & 5.2 \\
\hline Interleukin-I $\beta$ (IL-I $\beta)$ & 4.3 \\
\hline Solute carrier family 17 (SLCI7A5) & 4.2 \\
\hline Insulin-like growth factor I & 3.3 \\
\hline Fucosyltransferase I & 3.3 \\
\hline Matrix metallopeptidase-2 (MMP-2) & 2.6 \\
\hline Colony stimulating factor 2 (G-CSF-2) & 2.0 \\
\hline \multicolumn{2}{|l|}{ Lineage specific genes } \\
\hline \multicolumn{2}{|l|}{ "Osteogenic" genes } \\
\hline T-box 5 & 59.2 \\
\hline Bone morphogenetic protein-2 (BMP-2) & 17.0 \\
\hline Bone morphogenetic protein-6 (BMP-6) & 8.1 \\
\hline HNFI homeobox A & 8.0 \\
\hline Runt-related transcription factor 2 & 2.6 \\
\hline PTK2 protein tyrosine kinase 2 & 2.3 \\
\hline \multicolumn{2}{|l|}{ "Adipogenic" genes } \\
\hline Peroxisome proliferator-activated receptor (PPARG) & 13.7 \\
\hline \multicolumn{2}{|l|}{ "Chondrogenic" genes } \\
\hline Sex determining region Y (SRY)-box (SOX9) & 28.8 \\
\hline Growth differentiation-7 (GDF-7) & 6.4 \\
\hline Integrin, alpha $X(C D|| c)$ & 4.1 \\
\hline
\end{tabular}


TABLE 2. Downregulated expression of PDLSC genes in K-M versus FBS-M

\begin{tabular}{lc}
\hline Functional gene grouping & Fold decrease \\
\hline Stem cell associated genes & \\
$\quad$ Markers of "stemness" & \\
$\quad$ Fibroblast growth factor 2 (FGF-2) & 2.6 \\
MSC specific markers & 2.2 \\
$\quad$ Integrin, alpha 6 & 3.1 \\
Other MSC associated genes & 2.4 \\
$\quad$ Microphthalmia-associated transcription factor & \\
$\quad$ Interleukin-6 (IL-6) & 13.5 \\
Lineage specific genes & 4.2 \\
"Chondrogenic" genes & Bone morphogenetic protein-4 (BMP-4) \\
"Myogenic" genes & \\
$\quad$ Jagged I (JagI) & \\
\hline
\end{tabular}

and mesenchymal stem cell associated genes (Table 2). Differential expression (up- and down-regulation) of lineage specific genes is also seen between the two culture conditions, but only for a few lineage specific genes (Tables I and 2). In analysis of differential gene expression of SHEDS grown in the two different media, there appeared to be the same degree of up- and down-regulation of different "stemness" associated genes and lineage specific genes (Tables 3 and 4). Taken together, these data suggest that while expansion of SHEDs in K-M resulted in differential expression of different genes associated with "stemness" and lineage specific differentiation, there appeared to be no net difference in the number of up- and down-regulated genes. Yet, for PDLSCs cultured between the two conditions, the K-M appeared to "hold" cells in a greater state of "stemness," as evidenced by the upregulation of "stemness" associated genes when cultured in this media.

\section{Osteogenic potential of PDLSCs and SHEDs in K-M}

Because PDLSCs and SHEDs have demonstrated the capacity for osteogenic differentiation when cultured in the presence of osteogenic inductive factors, we examined the ability of K-M to support the growth of PDLSCs and SHEDS while maintaining their capacity for osteogenic differentiation. To evaluate this, cells were expanded for 7 days in either K-M or FBS-M and then

TABLE 3. Upregulated expression of SHED genes in K-M versus FBS-M

\begin{tabular}{lc}
\hline Functional gene grouping & Fold increase \\
\hline Stem cell associated genes & \\
Markers of "stemness" & \\
Insulin & 2.0 \\
MSC specific markers & 29.2 \\
VEGFR-2/KDR & 7.1 \\
Alanyl aminopeptidase & 2.2 \\
Prominin I & 2.1 \\
NT5E (CD73) & 5.0 \\
Other MSC associated genes & 4.9 \\
Colony stimulating factor 3 (G-CSF-3) & 3.5 \\
Hepatocyte growth factor & 2.6 \\
Nestin & 2.5 \\
Solute carrier family I7 (SLCI7A5) & 2.4 \\
Von Willebrand factor & 2.3 \\
Colony stimulating factor 2 (G-CSF-2) & 2.1 \\
Vascular endothelial growth factor-A (VEGF-A) & \\
Annexin A5 & \\
Lineage specific genes & 2.4 \\
"Osteogenic" genes & 2.3 \\
Bone morphogenetic protein-2 (BMP-2) & 10.8 \\
PTK2 protein tyrosine kinase 2 & \\
"Adipogenic" genes & 4.5 \\
Peroxisome proliferator-activated receptor (PPARG) \\
"Chondrogenic" genes \\
Sex determining region Y (SRY)-box (SOX9)
\end{tabular}

TABLE 4. Downregulated expression of SHED genes in K-M versus FBS-M

\begin{tabular}{lc}
\hline Functional gene grouping & Fold decrease \\
\hline Stem cell associated genes & \\
Markers of "stemness" & 4.9 \\
Fibroblast growth factor 2 (FGF-2) & 3.9 \\
POU class 5 homeobox I (Oct-4) & \\
MSC specific markers & 44.8 \\
Vascular cell adhesion molecule-I (CDI06) & 3.7 \\
$\quad$ Activated leukocyte cell adhesion molecule & \\
Other MSC associated genes & 67.8 \\
Interleukin-6 & 7.7 \\
Brain-derived neurotrophic factor (BDNF) & 7.3 \\
Insulin-like growth factor I & 5.3 \\
Collagen, type I, alpha I & 4.1 \\
Protein tyrosine phosphatase, receptor & 3.2 \\
$\quad$ Nudix & 2.8 \\
Intercellular adhesion molecule I & 2.6 \\
Microphthalmia-associated transcription factor matrix & 2.6 \\
Metallopeptidase-2 & 2.0 \\
Interleukin- I $\beta$ (IL-I $\beta$ ) & \\
Lineage specific genes & \\
"Osteogenic" genes & 3.3 \\
SMAD specific E3 ubiquitin protein & 2.4 \\
Fibroblast growth factor-I0 & \\
"Adipogenic" genes & 2.1 \\
Ras homologue gene family member (RHOA) & \\
"Chondrogenic" genes & 5.3 \\
Growth differentiation-5 (GDF-5) & 2.2 \\
Bone morphogenetic protein-4 (BMP-4) & 2.1 \\
Growth differentiation-6 (GDF-6) & \\
\hline
\end{tabular}

cultured in osteoinductive media (containing FBS) for 7 days. Alkaline phophatase activity was analyzed quantitatively following I week of culture in osteoinductive media and in both SHEDs and PDLSCs, there were no differences in Alk-P activity between cells expanded in K-M versus those expanded in FBS-M (Fig. 3a,b). This demonstrated that both cell types maintained their capacity for osteogenic differentiation following cell expansion in K-M.

\section{Maintenance of PDLSC and SHED multilineage potential in K-M}

PDLSCs and SHEDS were assessed for their capacity to differentiate towards different cellular lineages following cell expansion in K-M and FBS-M. Lineage specific induction under traditional adipogenic, chondrogenic, and osteogenic conditions was performed and these conditions incorporated serum in the induction media. Following I week of induction, RT-PCR was performed to examine gene expression of adipogenic (PPAR 2 2, LPL) (Fig. 4a) and chondrogenic (SOX9, coll. II) (Fig. 4b) markers in their respective conditions. Additionally, PDLSCs and SHEDs were stained with Von Kossa, Alcian blue, and Oil Red O. In control culture conditions, Von Kossa, Alcian blue, and Oil Red O staining were all negative. Under osteogenic culture conditions, PDLSCs expanded in either FBS-M or K-M exhibited a similar pattern of Von Kossa staining, which indicated deposition of mineralized matrix indicative of osteoblasts (Fig. 5a). Similarly, in cells grown under chondrogenic conditions following culture expansion in either FBS-M or K-M, the presence of chondrogenic proteoglycans was indicated by positive Alcian blue staining (Fig. 5a), confirming chondrogenic differentiation. In adipogenic conditions, Oil Red O staining was used to detect intracellular lipid-rich vacuoles and morphological changes in cell shape. The results confirmed that under these conditions, PDLSCs expanded in either FBS-M or K-M exhibited no difference in their capacity to differentiate toward an adipogenic lineage (Fig. 5a). As was the case with the PDLSCs, SHEDs expanded in FBS-M or K-M exhibited comparable levels of differentiation towards osteogenic, chondrogenic, and adipogenic lineages as 


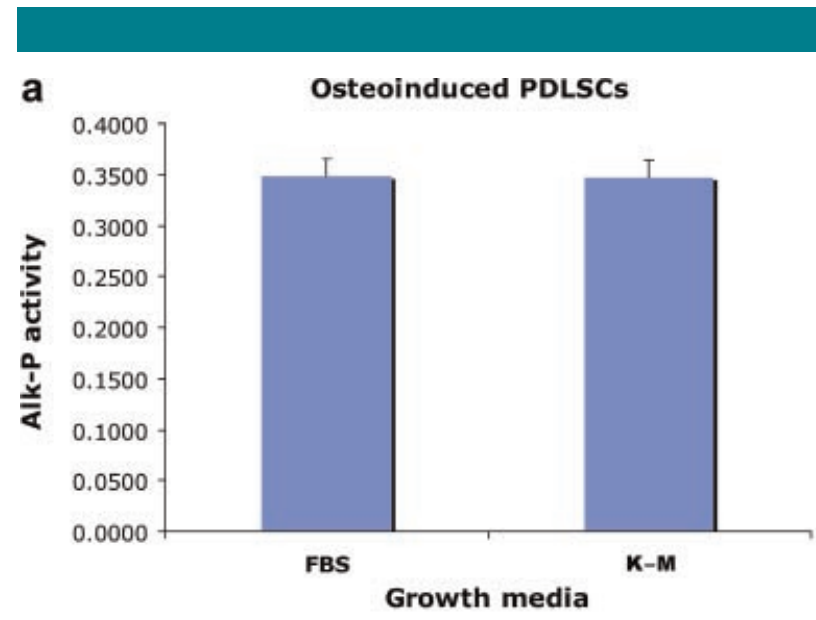

b

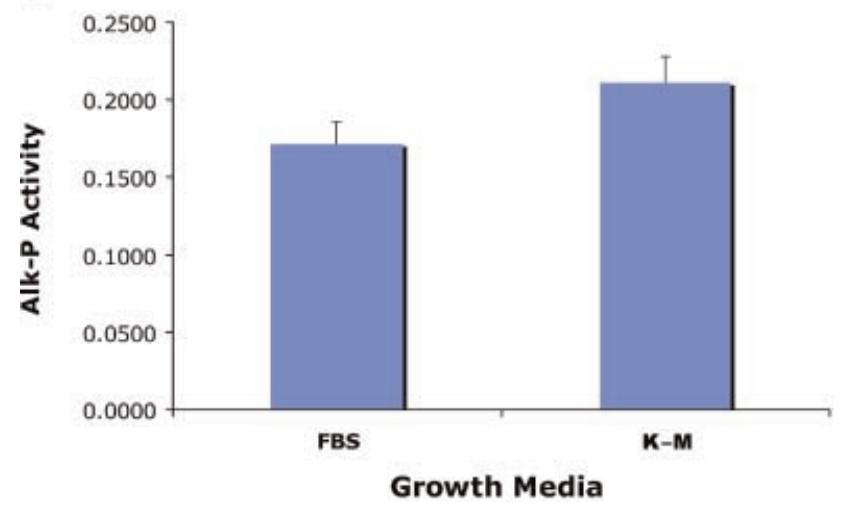

Fig. 3. Osteogenic potential of PDLSCs and SHEDs following expansion in K-M + FN. Alkaline phosphatase activity representing the osteogenic induction potential of (a) PDLSCs and (b) SHEDs following culture expansion in either FBS-M or K-M and I week induction in conventional osteogenic induction media (containing FBS). [Color figure can be viewed in the online issue, which is available at wileyonlinelibrary.com.]

evidenced through similar patterns of Von Kossa, Alcian Blue, and Oil Red $\mathrm{O}$ staining (Fig. 5b).

\section{Discussion}

Oral-derived stem cells have clinical potential for cell therapy applications in craniofacial regeneration; yet, one of the possible limitations with the clinical utility of these cells is that all current cell culture protocols for their expansion incorporate animal sera. In this report, we describe the development of a chemically defined, serum-free media (K-M) for the cell expansion of dental-derived stem cells. PDLSCs and SHEDs cultured in K-M proliferated at rates faster than when these cells were cultured in media containing serum (FBS-M). Microarray analyses showed that overall, PDLSCs and SHEDs in K-M expressed more "stemness" markers, when compared to those cells in FBS-M. Finally, PDLSCs and SHEDs were able to maintain their capacity for osteogenic differentiation as well as their multilineage potential following culture in K-M.

It has been well-established that the components of serum contain rich nutrients and growth factors which support cell growth in culture (Price and Gregory, 1982; Satija et al., 2007). Yet, in the context of clinical applications, efforts to develop chemically defined, serum-free media to support growth of

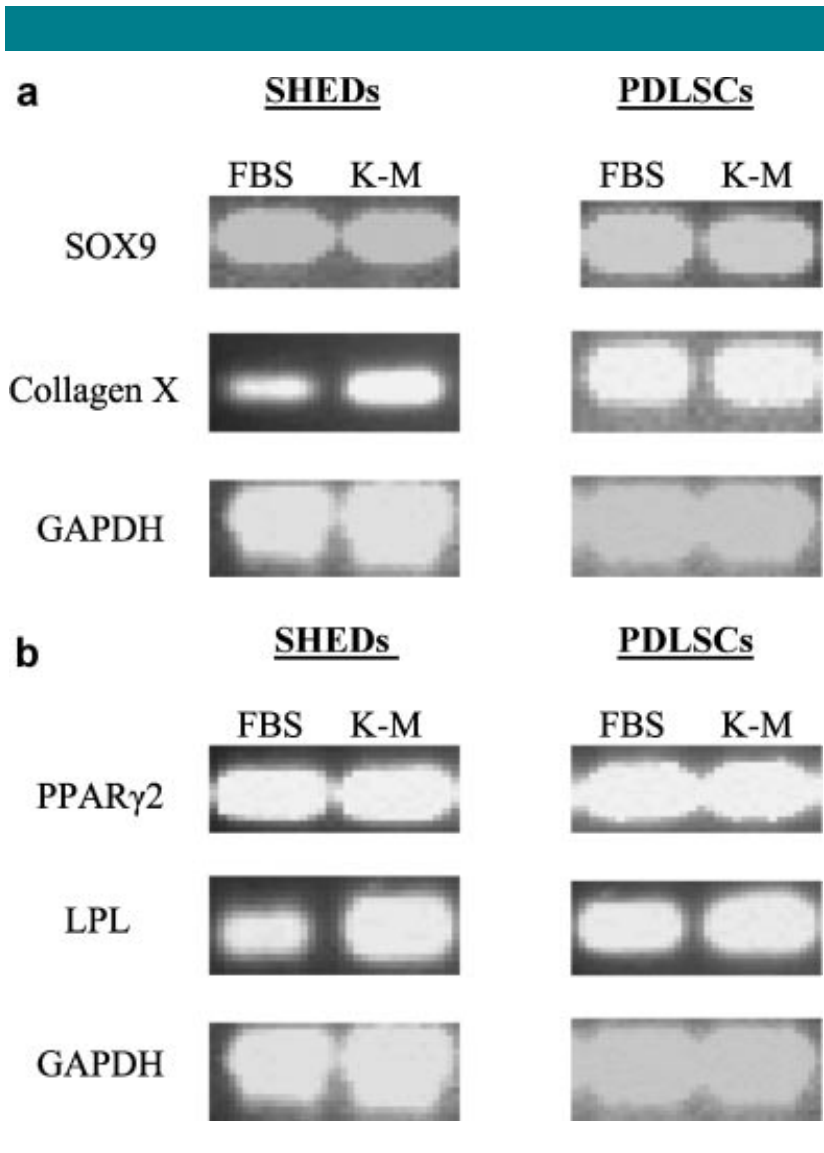

Fig. 4. K-M expanded PDLSC and SHED expression of lineage specific genes following adipogenic and chondrogenic induction. Following I week of induction, RT-PCR was performed to examine gene expression of (a) adipogenic (PPAR $\gamma 2$, LPL) and (b) chondrogenic (SOX9, coll. II) markers in their respective conditions.

different mesenchymal cell types are not new (Koller et al., 1998; Sotiropoulou et al., 2006; Mannello and Tonti, 2007). From a biology standpoint, the development of serum deprived growth media enables the study of growth factors, hormones and other compounds on cell cultures without the confounding effects of the possible presence of these components in serum (Lennon et al., 1995). Serum-free media has been examined for the cell expansion of bone marrow-derived stromal cells, and more recently, commercially developed serum-free media and serum substitutes have been developed for these cells. Despite the variety of different formulations examined, there appear to be a few common elements of animal sera to which all serumfree media formulations aim to replace or substitute, including: vitamins, hormones, transport proteins, essential elements, lipids, and growth factors. Because marrow derived mesenchymal stem cells share similar properties with certain populations of oral-derived stem cells, we took a similar approach in our efforts to develop a serum-free media for oral-derived stem cells. Replacement of an often overlooked component of serum, vitamins, served as the rationale in using IMDM media as the basal media. It contains high concentrations of vitamins and glucose, relative to other commonly used basal media (i.e., DMEM, $\alpha$ MEM) for cell culture. Another important source of key components was derived from the SITE 3 supplement, which provided transferrin and a source of lipids and trace elements. Transferrin, due to its iron-binding properties, is a critical component of chemically defined media due to its ability to transport iron (an essential trace element) 

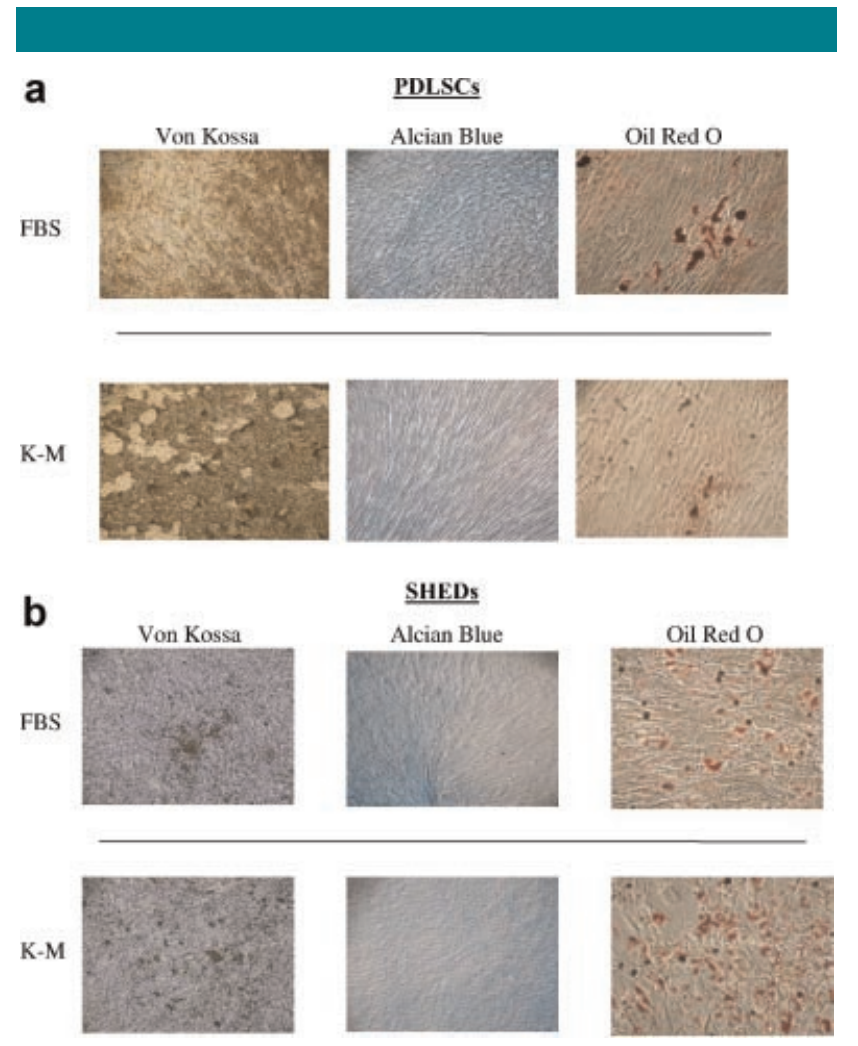

Fig. 5. Multipotency of PDLSCs and SHEDs following expansion in K-M + FN. a: Following culture expansion in either FBS-M or K-M, PDLSCs were induced to differentiate in osteogenic, chondrogenic, and adipogenic media; photomicrographs show multipotent mesenchymal differentiation as measured by phenotypic expression of osteogenic mineralized matrix (Von Kossa), chondrogenic proteoglycans (Alcian blue), and adipogenic lipid vacuoles (Oil Red O) (images shown at $200 \times$ magnification). b: Von Kossa, Alcian blue, and Oil Red $O$ staining of induced (osteogenic, chondrogenic, adipogenic) SHEDs following culture expansion in FBS-M or K-M. [Color figure can be viewed in the online issue, which is available at wileyonlinelibrary.com.]

across cell membranes (Barnes and Sato, 1980; Lennon et al., 1995). Selenium, also an essential trace element, is contained within the SITE 3 supplement as well, and is involved in cell growth (McKeehan et al., 1976). The other components of SITE 3 are insulin, ethanolamine, linoleic acid, and oleic acid. Insulin is a hormone that promotes the uptake of glucose and amino acids and serves as a mitogen for in vitro culture of cells due to its role in fatty acid and glycogen syntheses. The fatty acids (ethanolamine, linoleic acid, and oleic acid) are important nutrients for many cells in that they are involved in cell growth and also serve as key components of the cell membrane (Murakami et al., 1982; Kovar, 1987). Finally, serum bovine albumin (BSA) is contained within SITE 3 and due to the critical role it plays as a fatty acid carrier (Guilbert and Iscove, 1976; Nilausen, I978), additional BSA was directly added to the K-M culture medium at a concentration of $0.2 \%$.

Other key components of the K-M media were ascorbic acid, exogenous hormones (PTH and hydrocortisone), and growth factors (PDGF, EGF, FGF). Though ascorbic acid is often incorporated into "osteoinduction media" for mesenchymal cells (Pittenger et al., 1999), historically, it has been implicated in the biosynthesis of extracellular matrix components such as collagen and increases the cell proliferation of mesenchymal cells in culture (Hata and Senoo, 1989; Harada et al., 1991). PTH has been shown to be required for serum-free growth of cell cultures (Bottenstein et al., 1979) and in testing of 37 lots of fetal bovine serum, Price and Gregory found that serum lots contained on average, I,718 pg/ml, with ranges between 85 and $6,180 \mathrm{pg} / \mathrm{ml}$ (Price and Gregory, 1982). Thus, we incorporated this into the K-M but in comparison to when it was not added to the media, no effects were observed on proliferation and gene expression of mesenchymal markers (data not shown). On the other hand, though we did not perform separate studies with or without inclusion of growth factors, inclusion of PDGF, EGF, and $\mathrm{b}-\mathrm{FGF}$ in serum-free medium for bone marrow derived mesenchymal stem cells has been shown to be critical for cell proliferation and in vitro colony-forming potential (Gronthos and Simmons, 1995; Lennon et al., I995; Kuznetsov et al., 1997). Through the utilization of blocking antibodies in serum-free media containing marrow stromal cell conditioned media, Kuznetsov et al. determined that the proliferation of marrow stromal fibroblasts requires participation of at least four growth factors: PDGF, bFGF, TGF-beta, and EGF. These results are in accord with findings from Lennon et al., which demonstrated that addition of PDGF and FGF to serum-free cultures of mesenchymal stem cells are critical in maintaining proliferation rates comparable to rates seen when cells are cultured in FBS. In the context of colony forming potential (CFU-F), through a series of exhaustive experiments studying the effects of individual growth factors and growth factor combinations on colony formation of bone marrow derived stromal cells, Gronthos et al. determined that exogeneous growth factor inclusion into serum-free media is necessary for clonal growth and development (Gronthos and Simmons, 1995). Though we did not examine CFU-F potential in these studies, we did examine proliferation rates of SHEDs, PDLSCs, and DPSCs with the media Gronthos et al. used in their studies and did not see proliferation of oral-derived stem cells beyond Day 5 , with most of the cells beginning to die off and detach from the culture plates at this point. Though proliferation was observed in the K$M$, we saw an increase in initial cell non-adherence and cell detachment over time, relative to cells cultured in FBS-M. This observation served as the rationale to incorporate the FN coating step as part of the cell expansion process, attempting to enhance cell adherence through utilization of an ECM coating on the tissue culture plates. The role of cell adhesion molecules contained in serum, namely fibronectin, has long been established. These molecules play important roles in promotion of cell attachment, proliferation, and differentiation and as such, efforts are often made in order to recapitulate the effects of these factors through the use of fibronectin, laminin, and collagen (Steele et al., 1993; Mauney et al., 2006). In our system, we showed that the additional step of providing a FN coating upon which the cells could attach was pivotal in attaining cell (SHEDs, PDLSCs) proliferation rates in K-M comparable and greater than those seen in FBS-M.

Though it was clearly demonstrated that cells could be expanded in K-M on FN, it was more critical to determine if these cells could retain their multipotency following culture in K-M. When the switch was made to conventional "lineage-specific induction" conditions with the incorporation of FBS (Pittenger et al., 1999), PDLSCs and SHEDs exhibited the ability to differentiate down osteogenic, adipogenic, and chondrogenic pathways. Though the PDLSCs and SHEDs were able to retain their capacity for differentiation following culture in $\mathrm{K}-\mathrm{M}$, the observation of an increase in proliferation rate suggested that the cells were less differentiated while growing in K-M, hence, exhibiting higher proliferative capacity. Further support that K-M appeared to maintain the cells in a less differentiated state, or greater state of "stemness," was provided by the observation of greater expression of stemness markers during culture in K-M, particularly by the PDLSCs. Additionally, it should be noted that when attempts were made to osteogenically induce cells (as described in the Materials and Methods Section) while leaving in K-M, cells did not show 
the capacity for induction (data not shown), further suggesting that this media may be "holding" them in a greater state of "stemness." If, in fact, this is the case, it could hold implications for therapeutic approaches to utilization of these cells. Of particular interest are the PDLSCs, which demonstrated significant upregulation ( $>2$-fold) of 36 of the 84 stem cell associated genes analyzed when culture in K-M relative to FBS$M$, the majority of these being genes associated with "stemness" or "undifferentiated" stem cell phenotypes. Further studies need to be performed in order to more clearly elucidate this hypothesis based on these initial observations.

As noted, due to concerns regarding the use of animal sera in cell therapy applications, there have been efforts to develop serum-free media formulations for the culture of bone marrow derived mesenchymal cells for the exploitation of their clinical utility. Serum-free media also allow more in depth study of specific growth factors effects on cells without the confounding factor of the various unknown components and effects of animal sera. Though oral-derived stem cells have similarities to bone marrow derived stem cells in their phenotypes and regenerative applications, a distinct therapeutic advantage of oral-derived stem cells is their availability, in that they are derived from non-functional tissues (i.e., extracted teeth). Though these studies provide early evidence of the development of a serum-free media capable of supporting the expansion and multipotency of PDLSCs and SHEDs, the true test of efficacy will be to determine if these cells cultured in K-M can retain their regenerative potential in vivo. Another key point to address will be to determine if these cells can be harvested, isolated, and expanded without ever being exposed to animal sera and further, if this impacts immunomodulatory properties these cells have been shown to possess (Wada et al., 2009). Studies are currently being planned which aim to address these points and more rigorously elucidate some of the mechanistic effects of specific components of the K-M media on regulation of gene expression and modulation of cell phenotype.

\section{Acknowledgments}

The authors would like to thank the University of Michigan Comprehensive Cancer Center's DNA Microarray Core Facility and the Immunologic Monitoring Core at the University of Michigan Cancer Center. The authors would like to also acknowledge that D.K. holds a Career Award for Medical Scientist (CAMS) given by the Burroughs Wellcome Fund. The CAMS award supported this work.

\section{Literature Cited}

Agata H, Watanabe N, Ishii Y, Kubo N, Ohshima S, Yamazaki M, Tojo A, Kagami H. 2009. Feasibility and efficacy of bone tissue engineering using human bone marrow stromal cells cultivated in serum-free conditions. Biochem Biophys Res Commun 382:353-358. Barnes D, Sato G. 1980. Serum-free cell culture: A unifying approach. Cell 22:649-655.

Batouli S, Miura M, Brahim J, Tsutsui TW, Fisher LW, Gronthos S, Robey PG, Shi S. 2003. Comparison of stem-cell-mediated osteogenesis and dentinogenesis. J Dent Res 82:976981.

Battiwalla M, Hematti P. 2009. Mesenchymal stem cells in hematopoietic stem cell transplantation. Cytotherapy II:503-5I5.

Bottenstein J, Hayashi I, Hutchings S, Masui H, Mather J, McClure DB, Ohasa S, Rizzino A, Sato

G, Serrero G, Wolfe R, Wu R. 1979. The growth of cells in serum-free hormonesupplemented media. Methods Enzymol 58:94-109.

Freshney RI. 2000. Culture of animal cells. New York: Wiley-Liss, Inc.
Gronthos S, Simmons PJ. 1995. The growth factor requirements of STRO-I-positive human bone marrow stromal precursors under serum-deprived conditions in vitro. Blood 85:929-940.

Gronthos S, Mankani M, Brahim J, Robey PG, Shi S. 2000. Postnatal human dental pulp stem cells (DPSCs) in vitro and in vivo. Proc Natl Acad Sci USA 97:13625-13630.

Guilbert LJ, Iscove NN. 1976. Partial replacement of serum by selenite, transferrin, albumin and lecithin in haemopoietic cell cultures. Nature 263:594-595.

Haack-Sorensen M, Friis T, Bindslev L, Mortensen S, Johnsen HE, Kastrup J. 2008. Comparison of different culture conditions for human mesenchymal stromal cells for clinical stem cell therapy. Scand J Clin Lab Invest 68:192-203.

Harada S, Matsumoto T, Ogata E. 1991. Role of ascorbic acid in the regulation of proliferation in osteoblast-like MC3T3-EI cells. J Bone Miner Res 6:903-908.

Hata R, Senoo H. 1989. L-Ascorbic acid 2-phosphate stimulates collagen accumulation, cell proliferation, and formation of a three-dimensional tissuelike substance by skin fibroblasts. J Cell Physiol 138:8-16.

Koller MR, Maher RJ, Manchel I, Oxender M, Smith AK. 1998. Alternatives to animal sera for human bone marrow cell expansion: Human serum and serum-free media. J Hematother $7: 413-423$.

Kovar J. 1987. Hybridoma cultivation in defined serum-free media: Growth-supporting substances. IV. Lipids and serum albumin. Folia Biol (Praha) 33:377-384.

Krebsbach PH, Robey PG. 2002. Dental and skeletal stem cells: Potential cellular therapeutics for craniofacial regeneration. J Dent Educ 66:766-773.

Kuznetsov SA, Friedenstein AJ, Robey PG. 1997. Factors required for bone marrow stroma fibroblast colony formation in vitro. Br J Haematol 97:56 I-570.

Lennon DP, Haynesworth SE, Young RG, Dennis JE, Caplan AI. 1995. A chemically defined medium supports in vitro proliferation and maintains the osteochondral potential of rat marrow-derived mesenchymal stem cells. Exp Cell Res 219:211-222.

Mannello F, Tonti GA. 2007. Concise review: No breakthroughs for human mesenchymal and embryonic stem cell culture: Conditioned medium, feeder layer, or feeder-free; medium with fetal calf serum, human serum, or enriched plasma; serum-free, serum replacemen nonconditioned medium, or ad hoc formula? All that glitters is not gold. Stem Cells 25:1603-1609.

Manolagas SC, Burton DW, Deftos LJ. 1981. I,25-Dihydroxyvitamin D3 stimulates the alkaline phosphatase activity of osteoblast-like cells. J Biol Chem 256:7| I5-7II

Mao J], Giannobile WV, Helms JA, Hollister SJ, Krebsbach PH, Longaker MT, Shi S. 2006 Craniofacial tissue engineering by stem cells. J Dent Res 85:966-979.

Mauney JR, Kirker-Head C, Abrahamson L, Gronowicz G, Volloch V, Kaplan DL. 2006 Matrix-mediated retention of in vitro osteogenic differentiation potential and in vivo boneforming capacity by human adult bone marrow-derived mesenchymal stem cells during ex vivo expansion. J Biomed Mater Res A 79:464-475.

McKeehan WL, Hamilton WG, Ham RG. 1976. Selenium is an essential trace nutrient for growth of WI-38 diploid human fibroblasts. Proc Natl Acad Sci USA 73:2023-2027.

Miura M, Gronthos S, Zhao M, Lu B, Fisher LW, Robey PG, Shi S. 2003. SHED: Stem cells from human exfoliated deciduous teeth. Proc Natl Acad Sci USA 100:5807-58।2.

Murakami H, Masui H, Sato GH, Sueoka N, Chow TP, Kano-Sueoka T. 1982. Growth of hybridoma cells in serum-free medium: Ethanolamine is an essential component. Proc Nat Acad Sci USA 79:1 I58-1162.

Nakamura S, Yamada Y, Baba S, Kato H, Kogami H, Takao M, Matsumoto N, Ueda M. 2008. Culture medium study of human mesenchymal stem cells for practical use of tissue engineering and regenerative medicine. Biomed Mater Eng 18:129-136.

Nilausen K. 1978. Role of fatty acids in growth-promoting effect of serum albumin on hamster cells in vitro. J Cell Physiol 96:I-14.

Pittenger MF, Mackay AM, Beck SC, Jaiswal RK, Douglas R, Mosca JD, Moorman MA Simonetti DW, Craig S, Marshak DR. 1999. Multilineage potential of adult human mesenchymal stem cells. Science 284:143-147.

Price PJ, Gregory EA. 1982. Relationship between in vitro growth promotion and biophysical and biochemical properties of the serum supplement. In Vitro 18:576-584.

Sadan O, Melamed E, Offen D. 2009. Bone-marrow-derived mesenchymal stem cell therapy for neurodegenerative diseases. Expert Opin Biol Ther 9:1487-1497.

Satija NK, Gurudutta GU, Sharma S, Afrin F, Gupta P, Verma YK, Singh VK, Tripathi RP. 2007 Mesenchymal stem cells: Molecular targets for tissue engineering. Stem Cells Dev 16:7-23.

Satija NK, Singh VK, Verma YK, Gupta P, Sharma S, Afrin F, Sharma M, Sharma P, Tripathi RP, Gurudutta GU. 2009. Mesenchymal stem cell-based therapy: A new paradigm in regenerative medicine. J Cell Mol Med 13:4385-4402.

Seo BM, Miura M, Gronthos S, Bartold PM, Batouli S, Brahim J, Young M, Robey PG, Wang CY, Shi S. 2004. Investigation of multipotent postnatal stem cells from human periodontal ligament. Lancet 364:149-155.

Shahdadfar A, Fronsdal K, Haug T, Reinholt FP, Brinchmann JE. 2005. In vitro expansion of human mesenchymal stem cells: Choice of serum is a determinant of cell proliferation, differentiation, gene expression, and transcriptome stability. Stem Cells 23:1357-1366.

Shi S, Bartold PM, Miura M, Seo BM, Robey PG, Gronthos S. 2005. The efficacy of mesenchymal stem cells to regenerate and repair dental structures. Orthod Craniofac Res $8.191-199$

Sotiropoulou PA, Perez SA, Salagianni M, Baxevanis CN, Papamichail M. 2006 Characterization of the optimal culture conditions for clinical scale production of human mesenchymal stem cells. Stem Cells 24:462-47I.

Steele JG, McFarland C, Dalton BA, Johnson G, Evans MD, Howlett CR, Underwood PA. 1993. Attachment of human bone cells to tissue culture polystyrene and to unmodified polystyrene: The effect of surface chemistry upon initial cell attachment. J Biomater Sci polystyrene: The effect

Wada N, Menicanin D, Shi S, Bartold PM, Gronthos S. 2009. Immunomodulatory properties of human periodontal ligament stem cells. J Cell Physiol 219:667-676. 